This is the moment to put in something like this since he seems to have forgotten the word "other".

"And the other car? What happened?"

The author points out that if a speech difficulty persists, however, or if the parent is concerned about the child's speech, it is advisable to consult a therapist, who will be able to give expert help if necessary.

This is a stimulating little book of interest I would say to parents and speech therapists, and of real value to the parents of a child with a speech problem.

\section{PAT ALLSOPP}

\section{STUTTERING - A SYMPOSIUM JON EISENSON, Editor}

\section{Harper and Brothers Publishers, New York. 1958}

This excellent book is a most significant contribution to the literature on stuttering. Jon Eisenson has as his basic premise the fact that, in order to find "some answers to the disorder or disorders of speech referred to as stuttering, many different points of view need to be presented." He has therefore selected the foremost authorities in the field to present their viewpoints and so attempt to clarify many of the problems associated with stuttering. The contributors to the symposium include Oliver Bloodstein, I. Peter Glauber, Joseph Sheehan, Robert West, Jon Eisenson and Charles van Riper. Wendell Johnson has written the preface. He has, in accordance with his semantic approach, attempted to indicate to the reader that much of the disagreement between authorities is to be found in their language usage.

Jon Eisenson, as editor, imposed upon each contributor the limitation that they should attempt to answer the following questions: "(1) What is stuttering? (2) What is the cause or what are the causes of stuttering? (3) In the light of your concept of stuttering, what are your suggestions for the treatment of stutterers."

It is Bloodstein's belief that stuttering is a "joint product of more than one factor." In his chapter "Stuttering as an Anticipatory Struggle Reaction" he gives a great deal of evidence to support this hypothesis. A resume of salient factors in therapy, including the handling of resistance, is presented in a most lucid way.

Glauber's chapter on "The Psychoanalysis of Stuttering" presents the viewpoint that stuttering is a neurotic disorder and therefore that an understanding of "unconcious mental life" is essential to the rehabilitation of the stutterer.

Sheehan presents his concept that stuttering is an approach-avoidance conflict. His scientific approach to the problem and the application of his hypothesis to therapy makes Sheehan's contribution one of the most valuable.

West titles his chapter "An Agnostics Speculations about Stuttering" because he doubts that "answers are availalble to certain fundamental questions." $\mathrm{He}$ attempts to relate stuttering to certain physical disorders thus emphasizing a physiololgical basis to stuttering.

Eisenson presents his own chapter on "A Perseverative Theory of Stuttering". According to his viewpoint stuttering "is a transient disturbance in communicative, propositional language usage." His emphasis of the communicative aspects of the disorder make this a most thought provoking chapter.

Van Riper's contribution to the sympoium takes the form of a report on "Experiments in Stuttering Therapy". It represents an exploration of the disorder for over twenty years. An almost day to day account is given of the therapy carried out with groups of stutterers. The practical knowledge to be gained from this chapter is great because the emphasis is on therapy.

It is my opinion that this book is an excellent addition to the available lilterature.

FRUME T. LUBINSKY

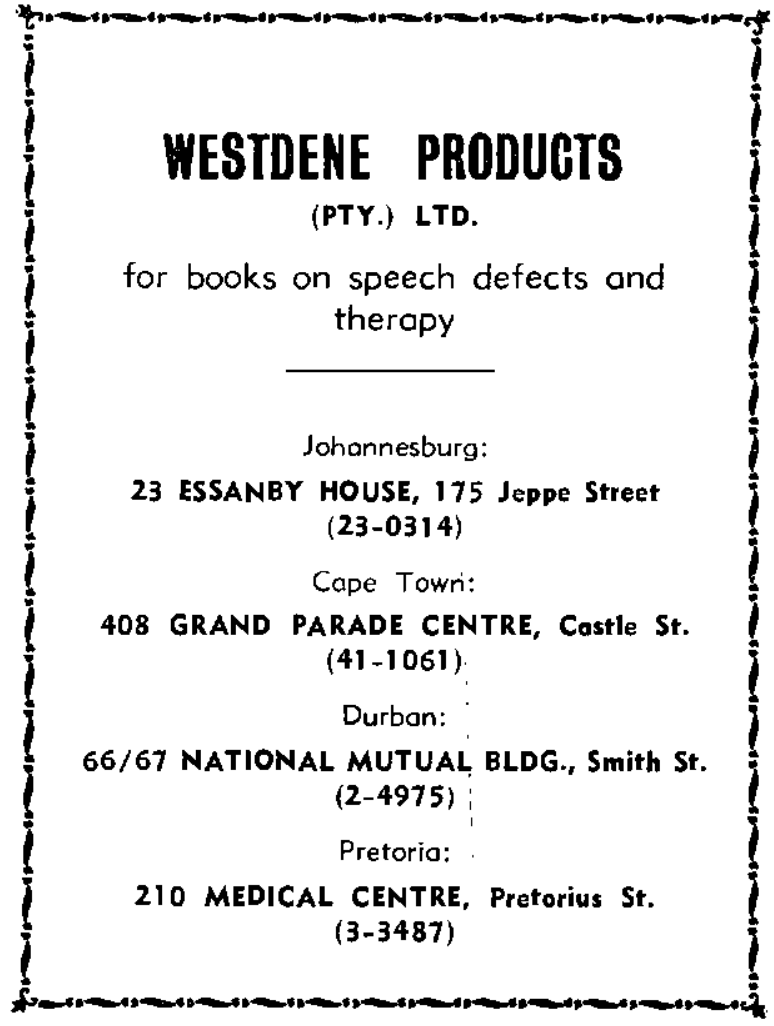

